\title{
Substituição de fígado bovino por glúten de milho, glúten de trigo e farelo de soja em rações para pós-larvas de piavas (Leporinus obtusidens) ${ }^{1}$
}

\author{
Replacement of bovine liver by corn gluten, wheat gluten and soybean meal \\ in rations for piava (Leporinus obtusidens) post-larvae
}

\author{
Jorge Eugenio da Silva Filipetto ${ }^{2}$ João Radünz Neto ${ }^{3}$ José Henrique Souza da Silva $^{4}$ \\ Rafael Lazzari ${ }^{5}$ Fábio de Araújo Pedron ${ }^{6}$ Cátia Aline Veiverberg ${ }^{6}$
}

\section{RESUMO}

Este trabalho foi realizado em duas etapas, com o objetivo de avaliar o efeito dos glutens de milho e trigo, e do farelo de soja, em substituição ao fígado bovino no crescimento de pós-larvas de piava (Leporinus obtusidens). $\mathrm{Na}$ primeira etapa, foram elaboradas rações com glúten de trigo ou milho, em substituição ao fígado bovino nos níveis de 25, 50 e 100\%. O glúten de trigo foi mais eficiente que o de milho como substituto do fígado bovino, sendo que até $40 \%$ de substituição proporciona maior tamanho e sobrevivência das pós-larvas. Na segunda etapa, foi avaliada a substituição dos $40 \%$ de glúten de trigo por farelo de soja, em níveis crescentes de 25, 50, 75 e 100\%. A substituição do glúten de trigo por farelo de soja em até 75\%, apresenta os melhores índices para pós-larvas de piava, aos 21 dias de idade.

Palavras-chave: piavas, pós-larvas, fontes protéicas, glúten de trigo, glúten de milho, farelo de soja.

\section{ABSTRACT}

The objective of the study was to evaluate the corn and wheat glutens and soybean meal in partial replacement to the bovine liver in granulated rations for rearing of piava post-larvae. In the first experiment meals were elaborated with wheat and corn glutens in substitution to the bovine liver in the levels of 25, 50 and 100\%. The wheat gluten was more efficient as substitute of the bovine liver, and up to $40 \%$ of replacement showed the highest fish size and survival. In the second experiment, the replacement of the wheat gluten by soybean meal in growing levels of 25, 50, 75 and $100 \%$ of the $40 \%$ of inclusion of the wheat gluten obtained in the first experiment was evaluated. The substitution of the wheat gluten by soybean meal up to $75 \%$ provides the highest size for piava post-larvae, at the 21 days of age.

Key words: piava, post-larvae, wheat gluten, protein sources, corn gluten, soybean meal.

\section{INTRODUÇÃO}

A piava (Leporinus obtusidens) ocorre nas bacias hidrográficas dos Rios Uruguai e Lago Guaíba, no Rio Grande do Sul. É uma espécie de que se tem pouco conhecimento sobre o desenvolvimento e hábito alimentar. A exemplo das demais espécies do Gênero Leporinus, a piava possui um hábito alimentar onívoro, alimentando-se de insetos (principalmente

${ }^{1}$ Parte da dissertação apresentada pelo primeiro autor à Universidade Federal de Santa Maria (UFSM) para obtenção do título de mestre em Zootecnia/Produção Animal.

${ }^{2}$ Zootecnista, Mestre em Zootecnia.

${ }^{3}$ Engenheiro Agrônomo, Doutor, Professor Adjunto, Departamento de Zootecnia, UFSM. E-mail-jradunzneto@smail.ufsm.br.

Autor para correspondência.

${ }^{4}$ Engenheiro Agrônomo, Doutor, Professor Adjunto, Departamento de Zootecnia, UFSM.

${ }^{5}$ Zootecnista, aluno do programa de Pós-graduação em Zootecnia, UFSM.

${ }^{6}$ Acadêmico do curso de Zootecnia, UFSM. 
Chironomidae), Bryozoa, restos de peixes e de vegetais (SANTOS, 2000). Outros autores, através de pesquisas de conteúdo alimentar, também classificaram a piava como peixe de hábito alimentar onívoro (ANDRIAN et al., 1994; RESENDE et al., 1998; HARTZ et al., 2000).

A fase inicial do desenvolvimento do peixe ou fase larval é um período muito importante, pois os requerimentos nutricionais são mais altos. Nesta fase, ocorre o rápido desenvolvimento corporal, e o uso de alimento com alto conteúdo protéico e de boa digestibilidade propicia o aporte nutricional necessário ao crescimento.

A alimentação natural dos viveiros usados em larvicultura de peixes pode não proporcionar rápido ganho inicial, pois é dependente de condições ambientais para produção do plâncton. As pesquisas em nutrição de peixes têm buscado o uso de fontes protéicas alternativas para substituição ou complementação da alimentação natural (RADÜNZ NETO, 1999). O uso de alimento seco balanceado apresenta-se como alternativa ao alimento natural na criação de pós-larvas de peixes por apresentar melhor condição de estocagem, facilidade de aquisição e maior uniformidade na qualidade das matérias-primas utilizadas.

RADÜNZ NETO et al. (2001), pesquisando o uso de fontes alimentares para pós-larvas de piavuçus (Leporinus macrocephalus) constataram que alimentos vivos como Artemia franciscana, não proporcionam bom desenvolvimento inicial para as pós-larvas. RIBEIRO \& HAYASHI (2000) avaliaram o desempenho e a sobrevivência de pós-larvas de piavuçu (Leporinus macrocephalus) usando três tratamentos: proteína de origem vegetal, proteína de origem animal, e alimentação natural. Os dois primeiros tratamentos foram melhores que a alimentação natural, indicando a possibilidade de espécies do gênero Leporinus utilizarem bem alimentos elaborados.

Segundo SKOMBERG et al. (1998), o glúten de trigo e o glúten de milho, na alimentação de peixes, são fontes protéicas indicadas para rações com baixo teor de fósforo, resultando na menor excreção de fósforo no meio ambiente e diminuindo a poluição aquática.

O glúten de milho 60 (GM) possui uma composição aproximada de $60,4 \%$ de proteína bruta com digestibilidade aparente de $87 \%$ e $4260 \mathrm{kcal} / \mathrm{kg}$ de energia digestível, para trutas (NRC, 1993). ALLAN et al. (2000) encontraram para o glúten de milho $62 \%$ de proteína bruta, com energia digestível e digestibilidade da matéria seca comparáveis à farinha de peixes, porém o conteúdo de aminoácidos essenciais é menor. Já o glúten de trigo (GT) possui alta digestibilidade e palatabilidade e pode substituir mais de $40 \%$ da farinha de peixe (HARDY, 1996) para peixes carnívoros. ALLAN et al. (2000) encontraram, para o glúten de trigo, um teor de proteína bruta de 76,9\% e uma digestibilidade aparente de $90 \%$ da matéria seca; o coeficiente de disponibilidade aparente para os aminoácidos foi de cerca de $100 \%$.

O objetivo do presente trabalho foi avaliar fontes protéicas vegetais em rações granuladas para pós-larvas de piavas (Leporinus obtusidens), testando o glúten de trigo, glúten de milho e farelo de soja em substituição ao fígado bovino, nos primeiros 21 dias de vida.

\section{MATERIAL E MÉTODOS}

No presente trabalho, foram realizados dois experimentos (A e B), com duração de 21 dias, no Laboratório de Nutrição de Peixes do Departamento de Zootecnia da Universidade Federal de Santa Maria, nos meses de dezembro de 2002 e fevereiro de 2003. A criação das pós-larvas de piava foi realizada em um sistema equipado com unidades experimentais com volume útil de $4 \mathrm{~L}$, com entrada e saída de água individual, e utilizando-se uma vazão inicial de 0,15L min $^{-1}$ chegando a $0,8 \mathrm{~L} \mathrm{~min}^{-1}$ na terceira semana experimental. O conjunto de bacias é acoplado a um sistema de recirculação de água constituído de um biofiltro, com sistema de aquecimento de água.

No experimento A, foram utilizadas póslarvas de piava com comprimento total médio de 4,5mm e peso estimado de $0,5 \mathrm{mg}$, distribuindo-se 190 peixes em 21 unidades experimentais; no experimento B, foram distribuídas 190 espécimes com um comprimento total médio de $4,5 \mathrm{~mm}$ e peso estimado de $0,5 \mathrm{mg}$, em 20 unidades experimentais.

No experimento A, utilizou-se como tratamento referência (ração FB) uma ração desenvolvida no Setor de Piscicultura da UFSM para larvicultura de jundiá (Rhamdia quelen) por PIAIA (1996) e ULIANA (1997). Neste experimento, foi avaliado o efeito da substituição de fígado bovino por níveis crescentes de glúten de trigo ou glúten de milho $(0,25$, 50, $100 \%$ ), em dietas granuladas para pós-larvas (Tabela 1). No experimento $B$, foi avaliada a substituição do melhor nível de inclusão do glúten de trigo (40\%), verificado no experimento $A$, por níveis crescentes de farelo de soja (FS) (0, 25, 50, 75 e $100 \%$ ) (Tabela 2).

As pós-larvas foram alimentadas diariamente a cada duas horas, a partir das 7 horas. O fotoperíodo empregado foi de 12 horas/luz. A alimentação inicial foi com ração com granulometria de $100-200 \mu m$ e a troca de 
Tabela 1 - Composição e análise bromatológica das rações do experimento A (\%).

\begin{tabular}{|c|c|c|c|c|c|c|c|}
\hline \multirow{2}{*}{ Ingredientes } & \multicolumn{7}{|c|}{ Níveis (\%) } \\
\hline & $\mathrm{FB}^{3}$ & $\mathrm{GT}_{25}{ }^{4}$ & $\mathrm{GT}_{50}$ & $\mathrm{GT}_{100}$ & $\mathrm{GM}_{25}{ }^{5}$ & $\mathrm{GM}_{50}$ & $\mathrm{GM}_{100}$ \\
\hline Fígado bovino $^{1}$ & 30,0 & 22,5 & 15,0 & 0,0 & 22,5 & 15,0 & 0,0 \\
\hline Glúten de milho & - & - & - & - & 7,5 & 15,0 & 30,0 \\
\hline Glúten de trigo & - & 7,5 & 15,0 & 30,0 & - & - & - \\
\hline Farelo de arroz & 8,0 & 8,0 & 8,0 & 8,0 & 8,0 & 8,0 & 8,0 \\
\hline Lecitina de soja & 2,0 & 2,0 & 2,0 & 2,0 & 2,0 & 2,0 & 2,0 \\
\hline Levedura cana & 57,0 & 57,0 & 57,0 & 57,0 & 57,0 & 57,0 & 57,0 \\
\hline Suplemento vit. e min. $^{2}$ & 3,0 & 3,0 & 3,0 & 3,0 & 3,0 & 3,0 & 3,0 \\
\hline Total (\%) & 100,0 & 100,0 & 100,0 & 100,0 & 100,0 & 100,0 & 100,0 \\
\hline Nutrientes & \multicolumn{7}{|c|}{ Composição centesimal analisada (\%) } \\
\hline Umidade & 10,80 & 8,50 & 9,30 & 10,40 & 8,20 & 10,00 & 10,20 \\
\hline Proteína bruta & 43,98 & 45,10 & 45,54 & 47,55 & 44,65 & 42,19 & 42,64 \\
\hline Mat. Mineral & 6,19 & 6,01 & 5,62 & 4,96 & 6,13 & 5,60 & 4,50 \\
\hline Extrato etéreo & 4,42 & 4,55 & 3,22 & 2,03 & 4,09 & 4,10 & 3,76 \\
\hline Fibra bruta & 0,92 & 0,83 & 1,03 & 0,78 & 0,88 & 0,86 & 0,94 \\
\hline Cálcio & 0,90 & 0,90 & 0,82 & 0,90 & 0,90 & 0,87 & 0,65 \\
\hline Fósforo & 1,10 & 1,04 & 0,92 & 0,82 & 1,06 & 1,00 & 0,81 \\
\hline
\end{tabular}

1- Quantidade referente à matéria parcialmente seca. Foi usado o fígado bovino, in natura, moído (66 \% de umidade), sendo o volume real de inclusão deste ingrediente corrigido ao teor de umidade na matéria natural.

2 - Composição por kg de produto: Acido fólico 50mg; Acido nicotínico 2200mg; Acido pantotênico 600mg; Cálcio 215mg; Cobalto 30mg; Cobre 300mg; Colina 17,5mg; Ferro 450mg; Flúor (Max.) 450mg; Fósforo 70g; Iodo 20mg; Lisina 5,8g; Magnésio 4,3g; Manganês 550mg; Selênio 45mg; Treonina 2900mg; Vitamina A 140.000UI; Vitamina B1 200mg; Vitamina B2 4000mg; Vitamina B6 160mg; Vitamina B12 400 $\mathrm{g}$; Vitamina C 5.000mg; Vitamina D3 10.000UI; Vitamina E 2000mg; Vitamina K3 100mg; Zinco 800mg.

3 - FB: Ração com fígado bovino.

4 - GM: Ração com glúten de milho em níveis crescentes de substituição do fígado bovino.

5 - GT: Ração com glúten de trigo em níveis crescentes de substituição do fígado bovino.

granulometria $(200-400 \mu \mathrm{m})$ ocorreu aos sete dias mantendo-se até o final dos experimentos.

Diariamente foram analisados os parâmetros físico-químicos: temperatura, oxigênio dissolvido, $\mathrm{pH}$, nitrito, amônia total e alcalinidade. Para as medidas de oxigênio e temperatura, foi utilizado oxímetro digital marca DIGIMED DM4; para nitrito, amônia, pH e alcalinidade utilizaram-se o conjunto de análises marca Alfa-Tecnoquímica. As leituras foram realizadas diariamente às $9 \mathrm{~h}$ para os dois experimentos.

O delineamento experimental adotado para o primeiro experimento foi inteiramente casualizado com sete tratamentos e três repetições. O delineamento experimental adotado para o segundo experimento foi inteiramente casualizado com cinco tratamentos e quatro repetições.

\section{RESULTADOS E DISCUSSÃO}

Os parâmetros de qualidade de água verificados nos dois experimentos estiveram dentro dos limites aceitáveis para a criação dos peixes. No experimento A, os valores médios (com DP) foram: Temperatura $=26^{\circ} \mathrm{C} \pm 0,63$; Oxigênio $=5,9 \mathrm{mg} \mathrm{L}^{-1} \pm 0,32$; Amônia total. $=0,2 \mathrm{mg} \mathrm{L}^{-1}$; Nitrito $=0,05 \mathrm{mg} \mathrm{L}^{-1}$; $\mathrm{pH}=7,36 \pm 0,22$; Alcalinidade total. $=36,32 \mathrm{mg} \mathrm{L}^{-1} \pm 3,51$. No experimento $B$ verificou-se: Temperatura= 26,5 ${ }^{\circ} \mathrm{C} \pm 0,34$; Oxigênio $=7,21 \mathrm{mg} \mathrm{L}^{-1} \pm 0,24$; Amônia total $=0,2 \mathrm{mg} \mathrm{L}^{-1}$; Nitrito $=0,05 \mathrm{mg} \mathrm{L}^{-1} ; \mathrm{pH}=7,48 \pm 0,11$; Alcalinidade total $=46 \mathrm{mg} \mathrm{L}^{-1} \pm 5,4$.

No experimento $A$, verificou-se que a substituição do fígado bovino por glúten de trigo foi mais eficiente do que por glúten de milho (Tabela 03). Neste experimento, o tratamento $\mathrm{GT}_{25}$ promoveu o maior peso $(110,80 \mathrm{mg})$ e o maior comprimento total; porém obtivemos a menor sobrevivência. Na substituição total do fígado bovino por glúten de milho (tratamento $\mathrm{GT}_{100}$ ), observou-se menor peso corporal $(18,73 \mathrm{mg})$ e o menor comprimento total. Dentre os tratamentos, $\mathrm{GT}_{25}$ e $\mathrm{GT}_{50}$ apresentaram os melhores índices de peso X sobrevivência (30,61 e 37,46, respectivamente). A taxa de crescimento específico (TCE), indicando a percentagem de crescimento obtida a cada dia do experimento, permitiu avaliar o 
Tabela 2 - Composição e análise bromatológica das rações do experimento B (\%).

\begin{tabular}{|c|c|c|c|c|c|}
\hline \multirow{2}{*}{ Ingredientes } & \multicolumn{5}{|c|}{ Níveis (\%) } \\
\hline & $\mathrm{FS}_{0}{ }^{3}$ & $\mathrm{FS}_{25}$ & $\mathrm{FS}_{50}$ & $\mathrm{FS}_{75}$ & $\mathrm{FS}_{100}$ \\
\hline Fígado bovino $^{1}$ & 17,0 & 17,0 & 17,0 & 17,0 & 17,0 \\
\hline Farelo de soja & 0,0 & 3,25 & 6,5 & 9,75 & 13,0 \\
\hline Glúten de trigo & 13,0 & 9,75 & 6,5 & 3,25 & 0,0 \\
\hline Farelo de arroz & 8,0 & 8,0 & 8,0 & 8,0 & 8,0 \\
\hline Lecitina de soja & 2,0 & 2,0 & 2,0 & 2,0 & 2,0 \\
\hline Levedura cana & 57,0 & 57,0 & 57,0 & 57,0 & 57,0 \\
\hline Suplemento vit. e min. $^{2}$ & 3,0 & 3,0 & 3,0 & 3,0 & 3,0 \\
\hline Total (\%) & 100,0 & 100,0 & 100,0 & 100,0 & 100,0 \\
\hline Nutrientes & \multicolumn{5}{|c|}{ Composição centesimal analisada (\%) } \\
\hline Umidade & 8,70 & 8,00 & 8,80 & 9,50 & 9,80 \\
\hline Proteína bruta & 44,19 & 43,75 & 43,52 & 40,66 & 40,88 \\
\hline Mat. Mineral & 6,15 & 6,20 & 6,42 & 6,57 & 6,76 \\
\hline Extrato etéreo & 3,73 & 3,65 & 4,55 & 4,45 & 3,81 \\
\hline Fibra bruta & 1,21 & 1,79 & 1,86 & 1,24 & ND \\
\hline Cálcio & 0,95 & 0,97 & 1,00 & 0,97 & 1,00 \\
\hline Fósforo & 0,99 & 0,99 & 1,01 & 1,02 & 1,04 \\
\hline
\end{tabular}

1 - Quantidade referente à matéria parcialmente seca. Foi usado o fígado bovino, in natura, (66 \% de umidade), sendo o volume real de inclusão deste ingrediente corrigido ao teor de umidade na matéria natural.

2 - Composição por kg de produto: Acido fólico 50mg; Acido nicotínico 2200mg; Acido pantotênico 600mg; Cálcio 215mg; Cobalto 30mg; Cobre 300mg; Colina 17,5mg; Ferro 450mg; Flúor (Max.) 450mg; Fósforo 70g; Iodo 20mg; Lisina 5,8g; Magnésio 4,3g; Manganês 550mg; Selênio 45mg; Treonina 2900mg; Vitamina A 140.000UI; Vitamina B1 200mg; Vitamina B2 4000mg; Vitamina B6 160mg; Vitamina B12

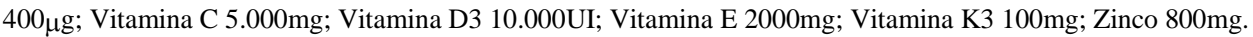

3 - FS: Substituição do glúten de trigo por farelo de soja em níveis crescentes.

desenvolvimento diário das pós-larvas. As melhores taxas foram observadas para o $\mathrm{GT}_{25}$ e $\mathrm{GT}_{50}(25,74 \mathrm{e}$ 24,37\%), mostrando a eficiência no ganho de peso diário, da substituição do fígado bovino por glúten de trigo em até $50 \%$.

No experimento A, houve uma perda significativa de pós-larvas que, devido ao tamanho diminuto e a pouca pigmentação nos primeiros dias de vida, misturam-se às sobras de alimentos, dificultando sua observação e são dadas por desaparecidas. Outra possibilidade para o desaparecimento de pós-larvas é o canibalismo resultante de crescimento heterogêneo, fruto da variabilidade genética resultante de reprodutores selvagens (SANTOS JÚNIOR \& SENHORINI, 1993).

Tabela 3 - Parâmetros de crescimento e sobrevivência das pós-larvas de piava (Leporinus obtusidens)*.

\begin{tabular}{|c|c|c|c|c|c|c|c|}
\hline Tratamentos & CT (mm) & $\mathrm{CP}(\mathrm{mm})$ & S (\%) & $\mathrm{P}(\mathrm{mg})$ & PS & FC & TCE $\left(\% \operatorname{dia}^{-1}\right)$ \\
\hline FB & $14,90^{\text {abc }}$ & $12,87^{\mathrm{abc}}$ & $31,75^{\mathrm{a}}$ & $61,23^{\mathrm{abc}}$ & $19,44^{\mathrm{b}}$ & $1,84^{\mathrm{ab}}$ & $22,89^{\mathrm{ab}}$ \\
\hline $\mathrm{GT}_{25}$ & $18,00^{\mathrm{a}}$ & $15,65^{\mathrm{a}}$ & $27,63^{\mathrm{a}}$ & $110,80^{\mathrm{a}}$ & $30,61^{a}$ & $1,81^{\mathrm{ab}}$ & $25,74^{\mathrm{a}}$ \\
\hline $\mathrm{GT}_{50}$ & $16,67^{\mathrm{ab}}$ & $14,60^{\mathrm{ab}}$ & $44,91^{\mathrm{a}}$ & $83,50^{\mathrm{ab}}$ & $37,46^{\mathrm{a}}$ & $1,81^{\mathrm{ab}}$ & $24,37^{\mathrm{a}}$ \\
\hline $\mathrm{GT}_{100}$ & $14,27^{\mathrm{abc}}$ & $12,10^{\mathrm{bc}}$ & $45,09^{\mathrm{a}}$ & $31,90^{\mathrm{bc}}$ & $14,38^{\mathrm{bc}}$ & $1,10^{\mathrm{b}}$ & $19,79^{\mathrm{bc}}$ \\
\hline $\mathrm{GM}_{25}$ & $13,70^{\mathrm{bc}}$ & $11,83^{\text {bcd }}$ & $38,07^{\mathrm{a}}$ & $36,70^{\mathrm{bc}}$ & $12,77^{\mathrm{bc}}$ & $1,41^{\mathrm{ab}}$ & $20,46^{\mathrm{bc}}$ \\
\hline $\mathrm{GM}_{50}$ & $11,83^{\mathrm{cd}}$ & $10,57^{\mathrm{cd}}$ & $32,11^{\mathrm{a}}$ & $25,43^{c}$ & $7,97^{\mathrm{C}}$ & $1,54^{\mathrm{ab}}$ & $18,71^{\mathrm{c}}$ \\
\hline $\mathrm{GM}_{100}$ & $9,70^{\mathrm{d}}$ & $8,63^{d}$ & $40,18^{a}$ & $18,73^{\mathrm{c}}$ & $7,34^{c}$ & $2,11^{\mathrm{a}}$ & $17,25^{c}$ \\
\hline $\mathrm{CV}$ & 9,51 & 9,18 & 41,21 & 35,59 & 23,43 & 16,79 & 6,32 \\
\hline $\mathrm{P}$ & 0,0001 & 0,0001 & 0,7872 & 0,0005 & 0,0001 & 0,0132 & 0,0001 \\
\hline
\end{tabular}

*Crescimento e sobrevivência de pós-larvas de piava alimentadas com fígado bovino (FB), substituído por glúten de trigo (GT) e glúten de milho (GM) em quantidades crescentes (\%).

a,b - Médias seguidas por letras diferentes na coluna, apresentam diferença significativa pelo teste de Tukey $(\mathrm{P}<0,05)$.

CT - comprimento total; CP - comprimento padrão; S - sobrevivência; P - peso; PS - peso versus sobrevivência;

FC - fator de condição; TCE - taxa de crescimento específico.

Tratamentos: FB:fígado bovino; GT:glúten de trigo; GM:glúten de milho.

Ciência Rural, v.35, n.1, jan-fev, 2005. 
Tabela 4 - Parâmetros de crescimento e sobrevivência das pós-larvas de piava (Leporinus obtusidens).*

\begin{tabular}{|c|c|c|c|c|c|c|c|}
\hline Tratamentos & $\mathrm{CT}(\mathrm{mm})$ & $\mathrm{CP}(\mathrm{mm})$ & S (\%) & P (mg) & PxS & FC & TCE(\% dia $\left.{ }^{-1}\right)$ \\
\hline $\mathrm{FS}_{0}$ & $13,90^{\mathrm{b}}$ & $11,90^{\mathrm{b}}$ & $50,53^{a}$ & $33,25^{a}$ & $14,57^{\mathrm{a}}$ & $1,17^{\mathrm{a}}$ & $19,99^{\mathrm{a}}$ \\
\hline $\mathrm{FS}_{25}$ & $14,38^{\mathrm{ab}}$ & $12,45^{\mathrm{ab}}$ & $48,42^{\mathrm{ab}}$ & $33,28^{\mathrm{a}}$ & $16,11^{\mathrm{a}}$ & $1,13^{\mathrm{a}}$ & $19,99^{\mathrm{a}}$ \\
\hline $\mathrm{FS}_{50}$ & $14,70^{\mathrm{ab}}$ & $12,70^{\mathrm{ab}}$ & $42,11^{\mathrm{ab}}$ & $38,20^{\mathrm{a}}$ & $17,04^{\mathrm{a}}$ & $1,17^{\mathrm{a}}$ & $20,65^{\mathrm{a}}$ \\
\hline $\mathrm{FS}_{75}$ & $15,23^{\mathrm{a}}$ & $13,23^{\mathrm{a}}$ & $42,76^{\mathrm{ab}}$ & $38,70^{\mathrm{a}}$ & $16,50^{\mathrm{a}}$ & $1,13^{\mathrm{a}}$ & $20,71^{a}$ \\
\hline $\mathrm{FS}_{100}$ & $14,25^{\mathrm{ab}}$ & $12,28^{\mathrm{ab}}$ & $40,00^{\mathrm{b}}$ & $36,57^{\mathrm{a}}$ & $15,74^{\mathrm{a}}$ & $1,36^{\mathrm{a}}$ & $20,44^{\mathrm{a}}$ \\
\hline $\mathrm{CV}$ & 3,56 & 3,99 & 8,19 & 11,76 & 12,71 & 15,43 & 3,76 \\
\hline $\mathrm{P}$ & 0,0287 & 0,0260 & 0,0005 & 0,3333 & 0,4067 & 0,3993 & 0,3125 \\
\hline
\end{tabular}

*Crescimento e sobrevivência de pós-larvas de piava alimentadas com glúten de trigo (40\% - FS ), substituído por farelo de soja em quantidades crescentes (\%).

a,b - Médias seguidas por letras diferentes na coluna apresentam diferença significativa pelo teste de Tukey (P<0,05).

${ }^{1}$ - CT - comprimento total; CP - comprimento padrão; S - sobrevivência; P - peso; PS - peso versus sobrevivência; FC - fator de condição; TCE - taxa de crescimento específico.

Na substituição de 25\% do fígado bovino por glúten de trigo, observou-se o melhor comprimento total (tratamento $\mathrm{GT}_{25}$ ). Entretanto, o aumento do nível de substituição do fígado bovino por glúten de trigo e/ ou do glúten de milho levou à diminuição do crescimento total e padrão. Na substituição de fígado bovino por glúten de milho, os resultados foram menos satisfatórios quando comparados ao tratamento FB. Estes resultados podem estar relacionados a deficiências nutricionais e/ ou à digestibilidade. PONGMANERAAT \& WATANABE (1991) encontraram para carpa comum 93,7 a 95,5\% de digestibilidade aparente para o glúten de milho. O glúten de milho é sabidamente deficiente em lisina (REGOST et al., 1999; ALLAN et al., 2000; STOREBAKKEN et al., 2000). MASUMOTO et al. (1996), avaliando a disponibilidade e a digestibilidade de aminoácidos de diferentes fontes protéicas, encontraram para o glúten de milho $63,10 \%$ de proteína bruta, porém com uma digestibilidade aparente de $49,7 \%$ e uma disponibilidade aparente de 46,8\%, para os aminoácidos essenciais. Segundo esses autores, as fontes protéicas de origem vegetal possuem alto conteúdo de carboidratos em relação às de origem animal.

A substituição do fígado bovino pelos glutens de trigo e de milho permitem concluir que o glúten de trigo é o melhor substituto. O nível de inclusão utilizado no $\mathrm{FS}_{0}$ do experimento B foi de $40 \%$ de substituição do fígado bovino. Este valor foi baseado no nível ótimo de substituição, obtido no experimento A, através do peso médio dos tratamentos com glúten de trigo. A análise de regressão do peso final das pós-larvas, para os tratamentos à base de glúten de trigo (experimento $\mathrm{A}$ ) mostrou que $\mathrm{o}$ melhor nível de substituição foi de $40 \%$, conforme a equação: $\mathrm{Y}=65,88122+1,43189 \mathrm{X}-0,01787 \mathrm{X}^{2}$.

No experimento $B$, observou-se que o comprimento total, comprimento padrão e sobrevivência foram diferentes $(\mathrm{P}<0,05)$ entre glúten de trigo e farelo de soja (Tabela 4). Entre os demais fatores não houve diferenças significativas. O tratamento $\mathrm{FS}_{75}$ apresentou o maior comprimento total e padrão em relação ao tratamento $\mathrm{FS}_{0}$; a maior taxa de sobrevivência ocorreu no tratamento $\mathrm{FS}_{0}$ diferindo apenas do tratamento com $100 \%$ de farelo de soja $\left(\mathrm{FS}_{100}\right)$. ESCAFFRE et al. (1997), estudando o uso de concentrado protéico de soja em pós-larvas de carpa (Cyprinus carpio), relatam que níveis de até $40 \%$ de substituição do concentrado de soja não afetam o crescimento ou a sobrevivência das pós-larvas. Porém, níveis de 60 a $70 \%$ de substituição retardam o crescimento. PIAIA (1996), em trabalho realizado com pós-larvas de jundiá (Rhamdia quelen), testou diversas rações experimentais com variação da fonte protéica, na qual as rações com farelo de soja continham 35\% de proteína, em média. Segundo esse autor os regimes à base de farelo de soja apresentaram baixa sobrevivência, independente das demais fontes protéicas, e isto pode ser devido a fatores antinutricionais encontrados no farelo de soja, quando este é mal tostado. Para as pós-larvas de piava, no experimento $\mathrm{B}$, o farelo de soja mostrou-se eficiente em substituição ao glúten de trigo.

\section{CONCLUSÕES}

As pós-larvas de piava podem aproveitar ingredientes de origem vegetal sem comprometer seu desenvolvimento inicial. A substituição de fígado bovino por glúten de trigo até $40 \%$, nas rações, proporcionou maior tamanho e sobrevivência aos 21 dias; a substituição do glúten de trigo por farelo de soja até $75 \%$ proporcionou maior peso das pós-larvas aos 21 dias, porém com menor sobrevivência. A 
substituição de fígado bovino por glúten de milho não se mostrou eficiente na criação de pós-larvas de piava (Leporinus obtusidens).

\section{AGRADECIMENTOS}

Agradecemos à Universidade de Cruz Alta (RS), por meio do Professor Alexandre Paz Cardoso, e ao Sr. Altamir Antonini pelo fornecimento de pós-larvas de piava; à VITAGRI, pela análise de rações; à Mig-Plus pelo fornecimento do Premix vitamínico mineral; à Granotec do Brasil pelo fornecimento do glúten de trigo; à União Farelos Representações Ltda, pelo fornecimento do glúten de milho; à Zillo Lorenzetti pelo fornecimento da levedura de cana.

\section{REFERÊNCIASBIBLIOGRÁFICAS}

ALLAN, G.L. et al. Replacement of fish meal in diets for Australian silver perch, Bidyanus bidyanus: I. Digestibility of alternative ingredients. Aquaculture, v.186, p.293-310, 2000 .

ANDRIAN, I.F. et al. Espectro alimentar e similaridade na composição da dieta de quatro espécies de Leporinus

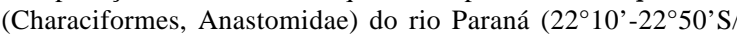

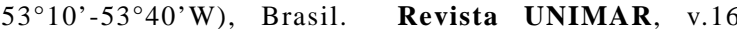
(suplemento), p.97-107, 1994.

ESCAFFRE, A.M. et al. Nutritional value of soy protein concentrate for larvae of common carp (Cyprinus carpio) based on growth performance and digestive enzyme activities. Aquaculture, v.153, p.63-80, 1997

HARDY, R.W. Alternate protein sources for salmon an trout diets. Animal Feed Science and technology, v.59, p.71-80, 1996.

HARTZ, S.M. et al. Alimentação da piava (Leporinus obtusidens) no Lago Guaíba, Porto Alegre, RS, Brasil. Pesquisa Agropecuária Gaúcha, v.6, n.1, p.145-150, 2000.

MASUMOTO, T. et al. Amino acid availability values for several protein sources for yellowtail (Seriola quinqueradiata). Aquaculture, v.146, p.106-119,1996.

NATIONAL RESEARCH COUNCIL - NRC. Nutritional requirements of fishes. Washington, DC : National Academy, 1993. 114p.

PIAIA, R. Efeito do uso de diferentes fontes protéicas e diferentes níveis de proteína sobre o crescimento de larvas do jundiá Rhamdia quelen. 1996. 47f. Dissertação (Mestrado em Zootecnia) - Universidade Federal de Santa Maria.

PONGMANEERAT, J.; WATANABE, T. Nutritive value of protein of feed ingredients for carp. Nippon Suisan Gakkaishi, n.57, p.503-510, 1991.

RADÜNZ NETO, J. Alimentação natural versus ração balanceada na larvicultura de peixes, Porto Alegre, RS, 1999. In: REUNIÃO DA SOCIEDADE BRASILEIRA DE ZOOTECnIA, 36., 1999, Porto Alegre, RS. Anais... Porto Alegre : Sociedade Brasileira de Zootecnia, 1999. p.119

RADÜNZ NETO, J. et al. Substituição parcial de levedura de cana-de-açúcar por farelo de soja na alimentação de larvas de piavuçu (Leporinus macrocephalus). Pesquisa Agropecuária Gaúcha, v.7, n.1, p.127-134, 2001.

REGOST, C. et al. Partial or total replacement of fish meal by corn gluten meal in diet for turbot (Psetta maxima). Aquaculture, v.180, p.99-11, 1999.

RESENDE, E.K. et al. Peixes herbívoros da planície inundável do rio Miranda, Pantanal, Mato Grosso do Sul, Brasil. Corumbá, MS : Empresa Brasileira de Pesquisa Agropecuária; Centro de Pesquisa do Pantanal, 1998. 24p. (EMBRAPA-CEPAP).

RIBEIRO R.P.; HAYASHI, C. Sobrevivência e desempenho de larvas de piavuçus (Leporinus macrocephalus) submetidas a diferentes dietas. In: SIMPÓSIO BRASILEIRO DE AQÜICULTURA - SIMBRAQ, 11., 2000, Florianópolis. Resumos... Florianópolis : ABRAq, 2000. p.162.

SANTOS, G.O. Aspectos importantes para a piscicultura do gênero Leporinus Spix, 1829 - uma revisão. Pesquisa Agropecuária Gaúcha, v.6, n.1, p.151-156, 2000.

SANTOS JÚNIOR, S.; SENHORINI, J.A. Efeito da separação mecânica por tamanho das larvas de Pacu, Piaractus mesopotamicus (Holmberg, 1887), na sobrevivência e homogeneidade dos alevinos. Boletim Técnico do CEPTA, v.6, n.2 p.11-22, 1993.

SKOMBERG, D.I. et al. Color and flavor analyses on fillets from farm-raised rainbow trout (Oncorhynchus mykiss) fed low-phosphorus feeds containing. Aquaculture, v.166, p.269277, 1998 .

STOREBAKKEN, T. et al. Digestibility of macronutrients, energy and amino acids, absorption of elements and absence of intestinal enteritis in Atlantic salmon, Salmo salar, fed diets with wheat gluten. Aquaculture, v.184, p.115-132, 2000 .

ULIANA O. Influência de diferentes fontes e níveis de lipídios sobre a criação de larvas de jundiá (Rhamdia quelen). 1997. 65f. Dissertação (Mestrado em Zootecnia) Curso de Pós-graduação em Zootecnia, Universidade Federal de Santa Maria. 